\title{
Using intuitive interaction technology to promote learning of mathematics in young children
}

\author{
Mei-Ling Chuang \\ Department of Early Childhood Care and Education, Cheng Shiu University, Kaohsiung City, Taiwan, R.O.C.
}

Email address:

einseinsster@gmail.com

\section{To cite this article:}

Mei-Ling Chuang. Using Intuitive Interaction Technology to Promote Learning of Mathematics in Young Children. Education Journal. Vol. 3, No. 1, 2014, pp. 1-6. doi: 10.11648/j.edu.20140301.11

\begin{abstract}
Modern technology has changed the methods of learning. It makes learning more interesting and more effective. This study explores the effectiveness of a project designed to improve young children's learning of mathematics, via intuitive interaction technology. While playing with this learning system, children can use their hands to point to virtual objects, or move them on the screen. Young children must have things that they can see, hear, touch, or feel, to help them learn new things. This project contains these features, which improve young children's learning. The instruments used by this study include: pretests, posttests and interviews. The participants were 43 students (ages from 5 to 6.5 years old), who all attended the same kindergarten. The results of ANCOVA show that playing with computer games yielded better results than traditional methods of learning.
\end{abstract}

Keywords: Mathematics Education, Digital Learning, Human-Computer Interaction (HCI)

\section{Introduction}

In recent years computers have played an increasing role in the lives of young children. In the past, concerns have been expressed, about whether computers are appropriate for children [2] [6]. However, what is of more concern today is whether computers can provide experiences that facilitate children's learning.

Educational computer games are considered to be effective learning tools, because they (1) use actions instead of explanations, (2) they stimulate personal motivation and satisfaction, (3) they can accommodate multiple learning styles and skills, (4) they reinforce mastery skills and (5) they provide interactive and decision-making contexts [9]. Games provide the functions of play and imitation, which, according to Piaget's theory, are both crucial to a child's intellectual development. Educational researches have suggested that computer games, with their greater motivational appeal and multimode representations, can be effective in mathematical learning for young children [13] [3] [19] [8]. Computer-assisted instruction can help children to practice arithmetic processes and drill and practice software can help young children improve their sorting and counting skills [3]. Some computer programs can improve kindergarten-aged children's analogical thinking [12].

Multimedia provides active engagement, via multiple presentational styles, such as text, voice, pictures and animation. A few empirical studies have shown that games can be effective in supplementing the teaching of arithmetical concepts, understanding and problem solving [17] [18]. Increasing volumes of research have shown that students can learn more fully, using well-designed multimedia presentations than by traditional learning methods [15] [20].

A joint position statement of the National Association for the Education of Young Children (NAEYC) and the National Council of Teachers of Mathematics (NCTM) has affirmed that high-quality, challenging and accessible mathematics education, for 3- to 6-year-old children, is a vital foundation for future mathematics learning [16]. It is widely accepted that mathematics development in the early years is critical to success and achievement in both school and life [1] [10].

Many of the higher quality media, for children ages 3 to 6 , have specific learning goals, use well-established and effective learning strategies and have been developed by experts who understand young children's developmental needs and abilities. However, not all digital media for young children use these well-established, effective learning strategies [14]. Although much research literature has identified the important strengths and limitations of digital media, for young children [11] [5] [21], much still remains to 
be learned about the benefits and drawbacks of these media and to the manner of their design. Little research has been conducted concerning young children's use of dynamic, interactive software, during early mathematical development. A study in reference [7] indicated that children who used dynamic, interactive software and virtual manipulation, to solve pattern-eliciting tasks, were more "experimental" and created more patterns and transformations than children who used traditional, real materials.

This study aims (1) to explore the effectiveness of a project designed to improve mathematics learning, by young children, using intuitive interaction technology, (2) to investigate the benefits and drawbacks of digital games, used in children's mathematics learning, (3) to investigate children's reactions to the technology, (4) to investigate the design of the computer game used in this study. While playing with this learning system, children could use their hands to point to virtual objects, or move them on the screen. The screen was $140 \mathrm{~cm}$ high and $245 \mathrm{~cm}$ wide. Young children must have things that they can see, hear, touch, or feel, to help them learn new things. This system uses these features to improve young children's learning. Relatively little is known about the potential of this technology to support teaching and learning by young children, so this research is important. The tools used in this study include: pretests, posttests and interviews.

\section{Method}

The participants were 43 students (12 girls and 31 boys, with ages from 5 to 6.5 years), who attended the same kindergarten. The students were randomly assigned to either an experimental group, or the control group. The experimental group comprised 21 students $(7$ girls and 14 boys), while the control group comprised 22 students ( 5 girls and 17 boys). A pretest was given to all subjects, before the experiment. The pretest was helpful in assessing the students' prior knowledge of mathematics and in testing the initial equivalence between groups. A posttest was given, to measure the effect of the new system.

Both the experimental group and the control group were subjected to identical pretests and posttests. These tests included 12 items, representing 8 different skills: addition and subtraction, with real objects; distribution; shape association; spatial association; identification of sequences; division of a circle and a rectangle and identification of left and right. Each item was scored as correct, or incorrect. The pretest and posttest used teaching materials and real objects. Between pretest and posttest the experimental group had four opportunities to play digital games, using intuitive interaction technology to learn mathematics. Each opportunity lasted about 10 minutes. At the same time, the control group was subjected to traditional mathematics teaching, from the researcher, and manipulated real materials. The digital games, played by the experimental group, mirrored the content of the traditional teaching, used for the control group.

\subsection{Procedure}

The study lasted for 3 months and used 43 students. The researcher gave individual pre-/post-training mathematics tests to each student, in a quiet room. The students were randomly assigned to either the experimental group, or the control group. The students in the experimental group were interviewed, after they had played the digital games. The interview included six items, designed to asses the students' reaction to the digital games and their attitudes to the use of intuitive interaction technology to learn mathematics, instead of traditional instruction. Three items examined the students' reactions to the digital games, used in the training (for example, Do you like the mathematics game? Why (or why not)? / What do you like most about the game? What don't you like the most about the game? Were you happy, when you got the right answer?) Three items compared experiences of learning using intuitive interaction technology and traditional methods.

\subsection{Intervention}

Children in the experimental group attended the intervention session in groups of 5 , or 6 . They took turns playing mathematical games, in front of the big screen. While one child played, the other children sat behind and waited. Each session lasted roughly 60 minutes. Each child attended 4 intervention sessions, over four weeks. The mathematical games were designed by the researcher.

The computer games were divided into an easy version (with numerals up to 5, or 6) and a difficult version (with numerals up to 12). 5-year-old children began with the easy version. 6 to 6.5 -year-old children were subjected to the difficult version. If the difficult version was too difficult, the researcher reverted to the easy version. The researcher taught the traditional mathematics curriculum to the children in the control group.

\section{Results}

\subsection{Scores of Pre- and Posttest}

The chief purpose of this study was to examine the effect of digital games that use intuitive interaction technology, on kindergarten-aged children's mathematical achievement. Firstly, the total scores and the items with significant values were analyzed. Three of the twelve items yielded significant values. Secondly, the items with results that were not significant were considered.

Table 1 shows that the interaction between the independent variable (scores of the posttest) and the covariate (scores of the pretest) was not significant, $F=0$. $629, \mathrm{p}=0.432>.05$. The slope for the experimental group is not significantly different from the slope for the control group. Therefore, the ANCOVA was allowed to run.

Upon eliminating the effects of the covariate, the ANCOVA analysis (table 2) showed that it is significant, with $\mathrm{F}=4.640, \mathrm{p}=0.037<.05$. The results show that the scores 
differed, after different treatments. The adjusted mean score for the experimental group (21.56) was better than that for the control group (20.44). The result shows that the level achieved using the computer games was better than that for the traditional curriculum.

With the exception of the total score, the ANCOVA analyses of three items in the pre- and posttest also yielded a value that was significant. The following is a discussion of these three items. Tables 3 and table 4 relate to the question, "How many balls plus how many balls is ten?" Table 3 indicates that the interaction between the independent variable and the covariate is not significant: $F=2.018$, $\mathrm{p}=0.163>.05$. The slope for the treatment group is not significantly different from the slope for the control group. Therefore, the ANCOVA was allowed to run.

Table 4 shows that, for the question, "How many balls plus how many balls is ten?", the analysis of covariance procedure produces a statistically significant F-value $(F=4.202, p=0.047<0.05)$. The adjusted mean score for the experimental group (1.90), in the posttest, was better than that for the control group (1.68). The result shows that, for addition, playing with computer games yields better results than traditional teaching methods.

In the pretest and posttest, the children played with balls, or real objects, to produce the answer. If the subject correctly answered the question, "How many balls plus how many balls is ten?", the experimenter added two balls in one box and asked the subject how many balls should be taken from the other box, so that the total number of balls in both boxes would be ten. The results for this scenario are shown in table 5 and table 6 . Table 5 shows that the interaction between the independent variable and the covariate is not significant: $\mathrm{F}=2.473, \mathrm{p}=0$ 124> .05. Therefore, the ANCOVA was allowed to run. The analysis of covariance (table 6) procedure produced a statistically significant F-value $(\mathrm{F}=4.779, \mathrm{p}=0.035<0.05)$. The adjusted mean score for the experimental group (1.67), in the posttest, was higher than that for the control group (1.36). The result shows that, for addition and subtraction, playing with computer games yields better results than traditional teaching methods.

Table 7 and table 8 are related to the question, "How must four white balls and six green balls be distributed to your mom and dad, so that each has the same amount of white balls and green balls?" Table 7 shows that the interaction between the independent variable and the covariate is not significant: $\mathrm{F}=0.470, \mathrm{p}=0.497>0.05$. Therefore, the ANCOVA was allowed to run. The analysis of covariance (table 8) procedure produced a statistically significant F-value $(\mathrm{F}=4.872, \mathrm{p}=0.033<0.05)$. The result showed that, for distribution, playing with computer games produced better results than traditional teaching methods. The adjusted mean score for the experimental group (1.90), at the posttest, was higher than that for the control group (1.64). The result shows that, for distribution, playing with computer games produced better results than traditional teaching methods.

\subsection{Analysis of Interviews}

The students in the experimental group were interviewed, after they had played the digital games. Each interview included six items, to assess students' reaction to the digital games and their attitudes to using intuitive interaction technology to learn mathematics, instead of traditional teaching methods. The questions and answers are detailed, as follows:

For the question, "Do you like the mathematics game?", all of the 21 students responded, "yes". As the reason, most students answered, "because it is fun", while some answered, "because I can learn something", "because I haven't played with it, before", or, "because I can learn how to divide things between people". To the question, "Do you like this kind of learning method?", most students $(85.7 \%)$ answered, "yes". To the question, "Would you like to learn mathematics, in this way, in the future?", 95.2\% responded, "yes". However, for the question, "Do you think learning in this way is more interesting than instruction by a teacher?", only $71.4 \%$ answered, "yes", and 9.5\% said, "no". 19\% said that both methods of learning were interesting.

\subsection{Discussion}

Although the ANCOVA analyses of the three items mentioned above were significant, the other 9 items (items 4 to 12 in the appendix) were not significant. They were not significant, for different reasons. The questions for items 4 and 5, which were about shape association and spatial association, were too easy for the subjects. Most subjects completed the questions correctly, in the pretest. Therefore, the pretest and posttest scores for these two items were identical. Conversely, the questions for items 7 to 9 (dividing a circle and a rectangle) were too difficult for some subjects. For those children who completed the tasks incorrectly, in the pretest, a teacher's explanation may prove more helpful than playing games.

Item 6 (identification of sequences) was not significant, for two reasons. The first reason is the same as that for items 4 and 5: some 4 and 5-year-old children who did not have prior knowledge could not understand the problem, merely by playing digital games. They needed an explanation from others. A combination of instruction and digital games may prove more useful to young children. The second reason was because of the inappropriate design of the computer games. The games used irregular shapes, which were too complicated for some children. Because of these two reasons, the children in the control group improved more, in the posttest, in relation to item 6 , than those in the experimental group.

Items 7, 8 and 9 tested the children's knowledge of shape division. The materials used in these three test items were a circular paper (for item 7), a rectangular paper (for items 8 and 9) and some sticks. In the pre- and posttest, children were asked to divide the circular and rectangular papers, using sticks. In the pretest, the correct answer for item 7 showed a division of the circular shape thus: $\oplus$. Incorrect 
answers provided by the children were: $\mathbb{D}, \mathbb{D}, \ominus$, $\ominus$, 令, etc. Without a teacher's explanation, some children had difficulty in understanding why divisions such as $\mathbb{D}$, or $\ominus$ are not equally divided, even though the circle is divided into four parts. Some children used 4 sticks to divide the circle into four parts, e.g. $\mathbb{D}$. Without explanation, some children also did not understand why their answer was wrong. For items 8 and 9 , the correct answers given by the

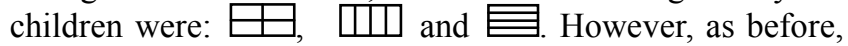
without explanation children also had difficulties in understanding why a rectangle divided as $\square$ is not equally divided, so they answered $\square$, in the pre- and posttest. For these items, the group that played with computer games was not better than the group with teacher assisted instruction, not because of the interactive technology, but because the software was not well designed. If squares, instead of rectangles, had been used for items 8 and 9, it might have been easier for children to answer correctly. Moreover, in the digital game, children selected the correct answer, form multiple choices. There were no options for $\mathbb{I}, \mathbb{I}, \ominus, \theta$,, , or $\varangle$. Therefore, children in the experimental group did not know that these answers were wrong, in the pre- and posttest. The control group used real materials and explanations from the researcher, so it was possible for them to higher scores for these items, in the posttest.

Items 10,11 and 12 tested children's appreciation of left and right, as well as the reflection of left and right, in a mirror. Students who already knew their right hand from their left hand, in the pretest, enjoyed the computer game. For the students who were confused about left and right, learning, merely by playing computer games, was difficult, especially for item 11, which concerned reflection in a mirror. A teacher's explanation could clarify the concept, so the control group performed better than the experimental group, in this task.

\section{Conclusion}

This study concludes that digital games and interactive technology can be effective tools, for mathematical learning by young children. Students can learn more effectively, using well-designed, multimedia presentations, than by traditional methods. The results of ANCOVA show that playing with computer games produces better results than traditional methods. Interviews with the subjects also revealed that children like to learn mathematics, using this intuitive interaction technology, because it makes learning fun. However, digital games are better suited to a role as supplemental learning material. When teaching difficult concepts, explanation by a teacher is necessary to children's understanding, so a combination of a teacher's explanation and computer games represents the best teaching method.

Further research might investigate the differences between the use of computer games in cooperative learning, in individual learning and in competitive learning, for an experimental group and a control group not exposed to multimedia (see for example, reference [20] [8]). If children learn mathematics, in a cooperative way, with computers, they may scaffold one another's learning.

\section{Acknowledgements}

Thanks many teachers work in kindergartens who give this study many suggestions. This work was supported by the National Science Council Taiwan under the Grant No. NSC 96-2622-S-230 -001-CC3.

\section{Appendix I}

Table 1. The Effect on Children's Mathematical Achievement of Learning with Intuitive Interaction Technology Tests of Effects, between Subjects Dependent Variable: Total Score for Posttest

\begin{tabular}{lccccc}
\hline Source & $\begin{array}{c}\text { Type III Sum } \\
\text { of Squares }\end{array}$ & df & $\begin{array}{c}\text { Mean } \\
\text { Square }\end{array}$ & F & P \\
\hline $\begin{array}{l}\text { Corrected } \\
\text { model }\end{array}$ & 92.225 & 3 & 30.742 & 10.751 & .000 \\
Intercept & 150.240 & 1 & 150.240 & 52.541 & .000 \\
Group & 3.435 & 1 & 3.435 & 1.201 & .280 \\
Pretest score & 59.642 & 1 & 59.642 & 20.858 & .000 \\
Interaction & 1.800 & 1 & 1.800 & .629 & .432 \\
Error & 111.520 & 39 & 2.859 & -- & -- \\
Corrected total & 203.744 & 42 & -- & -- & - \\
\hline
\end{tabular}

Table 2. The Effects on Children's Mathematical Achievement of Learning with Intuitive Interaction Technology: ANCOVA

\begin{tabular}{lccccc}
\hline Source & $\begin{array}{c}\text { Type III } \\
\text { Sum of } \\
\text { Squares }\end{array}$ & df & $\begin{array}{c}\text { Mean } \\
\text { Square }\end{array}$ & F & P \\
\hline $\begin{array}{l}\text { Covariate } \\
\text { (pretest) }\end{array}$ & 68.796 & 1 & 68.796 & 24.284 & .000 \\
Group & 13.145 & 1 & 13.145 & 4.640 & .037 \\
Error & 113.319 & 40 & 2.833 & -- & -- \\
\hline
\end{tabular}

Table 3. How many Balls plus how many Balls is ten? Tests of Effects between Subjects Dependent Variable: (Posttest) How many Balls plus how many Balls is ten?

\begin{tabular}{lccccc}
\hline Source & $\begin{array}{c}\text { Type III Sum } \\
\text { of Squares }\end{array}$ & df & $\begin{array}{c}\text { Mean } \\
\text { Square }\end{array}$ & F & P \\
$\begin{array}{l}\text { Corrected } \\
\text { model }\end{array}$ & 2.466 & 3 & .822 & 6.895 & .001 \\
Intercept & 2.794 & 1 & 5.794 & 48.597 & .000 \\
Group & .461 & 1 & .461 & 3.866 & .056 \\
Pretest score & 1.014 & 1 & 1.014 & 8.505 & .006 \\
Interaction & .241 & 1 & .241 & 2.018 & .163 \\
Error & 4.650 & 39 & .119 & -- & -- \\
Corrected total & 7.116 & 42 & -- & -- & -- \\
\hline
\end{tabular}


Table 4. How many Balls plus how many Balls is ten? ANCOVA

\begin{tabular}{lccccc}
\hline Source & $\begin{array}{c}\text { Type III } \\
\text { Sum of } \\
\text { Squares }\end{array}$ & df & $\begin{array}{c}\text { Mean } \\
\text { Square }\end{array}$ & F & P \\
\hline $\begin{array}{l}\text { Covariate } \\
\text { (pretest) }\end{array}$ & 1.153 & 1 & 1.153 & 9.427 & .004 \\
$\begin{array}{l}\text { Group } \\
\text { Error }\end{array}$ & .514 & 1 & .514 & 4.202 & .047 \\
\hline
\end{tabular}

Table 5. If two Balls are added to one Box, how many Balls should be taken from the other Box, so that the total number of Balls in both Boxes will be ten? Tests of Effects between Subjects

\begin{tabular}{lccccc}
\hline Source & $\begin{array}{c}\text { Type III } \\
\text { Sum of } \\
\text { Squares }\end{array}$ & df & $\begin{array}{c}\text { Mean } \\
\text { Square }\end{array}$ & F & P \\
\hline Corrected & 3.328 & 3 & 1.109 & 5.834 & .002 \\
model & 4.565 & 1 & 4.565 & 24.005 & .000 \\
Intercept & .941 & 1 & .941 & 4.949 & .032 \\
Group & 1.378 & 1 & 1.378 & 7.246 & .010 \\
Pretest score & .470 & 1 & .470 & 2.473 & .124 \\
Interaction & 7.416 & 39 & .190 & -- & - \\
Error & 10.744 & 42 & -- & -- & -- \\
Corrected & & & & & \\
total & &
\end{tabular}

Table 6. If two Balls are added to one Box, how many Balls should be taken from another Box, so that the total number of Balls in both Boxes will be ten? ANCOVA

\begin{tabular}{lccccc}
\hline Source & $\begin{array}{c}\text { Type III } \\
\text { Sum of } \\
\text { Squares }\end{array}$ & df & $\begin{array}{c}\text { Mean } \\
\text { Square }\end{array}$ & F & P \\
\hline $\begin{array}{l}\text { Covariate } \\
\text { (pretest) }\end{array}$ & 1.172 & 1 & 1.172 & 5.945 & .019 \\
$\begin{array}{l}\text { Group } \\
\text { Error }\end{array}$ & .942 & 1 & .942 & 4.779 & .035 \\
\hline
\end{tabular}

Table 7. How must four white Balls and six green Balls be distributed to your Mom and Dad, so that each has the same amount of white Balls and green Balls? Tests of Effects between Subjects

\begin{tabular}{lccccc}
\hline Source & $\begin{array}{c}\text { Type III } \\
\text { Sum of } \\
\text { Squares }\end{array}$ & df & $\begin{array}{c}\text { Mean } \\
\text { Square }\end{array}$ & F & P \\
\hline Corrected & 1.711 & 3 & .570 & 3.729 & .019 \\
model & 7.659 & 1 & 7.659 & 50.085 & .000 \\
Intercept & .274 & 1 & .274 & 1.793 & .188 \\
Group & .852 & 1 & .852 & 5.574 & .023 \\
Pretest score & .072 & 1 & .072 & .470 & .497 \\
Interaction & 5.964 & 39 & .153 & -- & -- \\
Error & 7.674 & 42 & -- & -- & - \\
Corrected & & & & & - \\
total & & &
\end{tabular}

Table 8. How must four white Balls and six green Balls be distributed to your Mom and Dad, so that each has the same amount of white Balls and green Balls?

\begin{tabular}{cccccc}
\hline Source & $\begin{array}{c}\text { Type III } \\
\text { Sum of } \\
\text { Squares }\end{array}$ & df & $\begin{array}{c}\text { Mean } \\
\text { Square }\end{array}$ & F & P \\
\hline $\begin{array}{c}\text { Covariate } \\
\text { (pretest) }\end{array}$ & .865 & 1 & .865 & 5.732 & .021 \\
Group & .735 & 1 & .735 & 4.872 & .033 \\
Error & 6.035 & 40 & .151 & -- & - \\
\hline
\end{tabular}

\section{Appendix II}

The 12 items in the pre- and posttest:

1. (Addition) How many balls plus how many balls is ten?

2. (Addition and subtraction) If two balls are added to one box, how many balls should be taken from the other box, so that the total number of balls in both boxes will be ten?

3. (Distribution) How must four white balls and six green balls be distributed to your mom and dad, so that each has the same amount of white balls and green balls?

4. (Shape association) Please put the triangular cards in the appropriate place, in the picture. $\bigotimes$

5. (Spatial association) Please arrange the cards on the right side, to form the same picture as the left side.

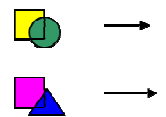

6. (Identification of Sequences) A factory produces differently shaped cookies, in a repeated sequence, what shape will come after the square? $\quad \square \triangle$ ० $\square \triangle$ ० $\triangle$ ० .......

7. (Shape division) How can a round cake be divided, equally, between four children?

8. (Shape division) How can a rectangular cake be divided, equally, between four children?

9. (Shape division) Can you divide the rectangular cake, equally, into four parts in a different way to that used in item 8 ?

10. Which hand is your left hand? Which hand is your right hand?

11. If I raise my right hand, which hand will the man in the mirror raise?

12. Please put the round cards to the left of the square.

\section{References}

[1] Bowman, B. T. (1999). Policy implications for math, science, and technology in early childhood. In Dialogue on early childhood science, mathematics, and technology education (pp. 40-49). Washington, DC: American Association for the Advancement of Science. Retrieved from http://www.project2061.org/publications/earlychild/online/c ontext/bowman.htm

[2] Clarke, V.A. (1990). Sex differences in computing participation: concerns, extent, reasons and strategies, Australian Journal of Education, 34(1), 52-66.

[3] Clements, D.H. \& Nastasi, B. K. (1993). Electronic media and early childhood education. In B. Spodek (Ed.), Handbook of research on the education of young children (pp.251-275). New York: Macmillan.

[4] Fox, J. (2007). International perspectives on Early Years Mathematics. In Watson, J. \& Beswick, K. (Eds.), Mathematics: Essential Research, Essential Practice, (Proceedings of the 30th annual conference of the Mathematics Education Research Group of Australasia), (Vol. 2, pp. 865-869), Adelaide, Australia: MERGA Inc. 
[5] Gimbert, B., \& Cristol, D. (2004). Teaching curriculum with technology: Enhancing children's technological competence during early childhood. Early Childhood Education Journal, 31(3), 207-216. doi: 10.1023/B:ECEJ.0000012315.64687.ee

[6] Healy, J. M. (1998). Failure to connect: how computers affect our children's minds - for better and worse. New York, NY: Simon \& Schuster.

[7] Highfield, K. \& Mulligan, J. (2007). The role of dynamic interactive technological tools in preschoolers' mathematical patterning. In Watson, J. \& Beswick, K. (Eds.), Mathematics. Essential Research, Essential Practice, (Proceedings of the 30th annual conference of the Mathematics Education Research Group of Australasia) (Vol. 1 pp. 372-381). Adelaide, Australia: MERGA Inc.

[8] Ke, F. (2006). Classroom goal structures for educational math game application. In Barab, S. A., Hay, K. E., \& Hickey, D. T. (Eds.), ICLS '06 Proceedings of the 7th international conference on Learning sciences (pp. 314-320), Bloomington, Indiana: International Society of the Learning Science.

[9] Kebritchi, M. \& Hirumi, A. (2008). Examining the pedagogical foundations of modern educational computer games to inform research and practice. Computers \& Education, 51(4), 1729-1743.

[10] Kilpatrick, J. , Swafford, J., \& Findell, B. (Eds.) (2001). Adding it up: Helping children learn mathematics. Washington, DC: National Academy Press.

[11] Kirkorian, H., Wartella, E. \& Anderson D. (2008). Media and young children's learning. The Future of Children, 18(1), $39-61$.

[12] Klein, P. \& Gal, O. N. (1992). Effects of computer mediation of analogical thinking in kindergartens, Journal of compter assisted learning, $8, \quad 244-254 . \quad$ doi: 10.1111/j.1365-2729.1992.tb00409.x
[13] Kromhout, O. M., \& Butzin, S. M. (1993). Integrating computers into the elementary school curriculum: an evaluation of nine project CHILD model schools, Journal of research on computing in education, 26, 55-69.

[14] Liebermann, D. A., Bates C. H., \& So, J. (2009). Young children's learning with digital media. Computers in the Schools, 26, 271-283.doi: 10.1080/07380560903360194

[15] Mayer, R. E. (2001). Multimedia learning. New York: Cambridge University Press.

[16] National Association for the Education of Young Children (2002). Early childhood mathematics: Promoting good beginnings. Position statement. Retrieved from http://www.naeyc.org/about/positions/psmath.asp

[17] Okolo, C. M. (1992). The effective of computer-assisted instruction format and initial attitude on the arithmetic facts proficiency and continuing motivation with learning disabilities. Exceptionality: A Research Journal, 3(4), 195-211.

[18] Ota, K. R. \& DuPaul, G. J. (2002). Take engagement and mathematics performance in children with attention-deficit hyperactivity disorder: Effects of supplemental computer instruction. School Psychology Quarterly, 17(3), 242-257. doi: $10.1521 /$ scpq.17.3.242.20881

[19] Prensky, M. (2001). Digital game-based learning. New York: McGraw-Hill Companies. R

[20] Weiss, I.; Kramarski, B. \& Talis, S. (2006). Effects of multimedia environments on kindergarten children's mathematical achievements and style of learning. Educational Media International, 43(1), 3-17.

[21] Yelland, N. (2005). The future is now: A review of the literature on the use of computers in early childhood education (1994-2004). Association for the Advancement of Computing in Edication (AACE) Journal, 13(3), 201-232. 